\title{
TECHNICAL ASPECTS RELATED TO THE APPLICATION OF SFM PHOTOGRAMMETRY IN HIGH MOUNTAIN
}

\author{
M. Scaioni a,b, J. Crippa ${ }^{\text {b }}$, M. Corti ${ }^{\text {b }}$, L. Barazzetti ${ }^{\text {a,b, },}$, D. Fugazza ${ }^{\text {c }}$, R. Azzoni ${ }^{\text {d }}$, M. Cernuschi ${ }^{\text {e }}$, G.A Diolaiuti ${ }^{d}$ \\ ${ }^{\text {a }}$ Dept. of Architecture, Built Environment and Construction Engineering (DABC), Politecnico di Milano \\ via Ponzio 31, 20133 Milano, Italy - email: \{marco.scaioni, luigi.barazzetti\}@polimi.it \\ ${ }^{\mathrm{b}}$ Polo Territoriale di Lecco, Politecnico di Milano \\ via G. Previati 1/c, 23900 Lecco, Italy - email: \{julien.crippa, manuel.corti\}@mail.polimi.it \\ ' Dept. of Earth Sciences ‘A. Desio’, Università degli studi di Milano, \\ via Mangiagalli 34, 20133 Milano, Italy - email: davide.fugazza@unimi.it \\ ${ }^{\mathrm{d}}$ Dept. of Environmental Science and Policy (DESP), Università degli studi di Milano \\ via Mangiagalli 34, 20133 Milano, Italy - email: guglielmina.diolaiuti@unimi.it \\ e Agricola 2000 S.C.P.A., 20067 Tribiano (MI), Italy - email: massimo.cernuschi@gmail.com
}

\section{Commission II, WG II/10}

KEY WORDS: Alpine Environment, Glaciology, Photogrammetry, Structure-from-Motion, UAV/UAS

\begin{abstract}
:
Structure-from-Motion (SfM) photogrammetry is a flexible and powerful tool to provide 3D point clouds describing the surface of objects. Due to the easy transportability and low-cost of necessary equipment with respect to laser scanning techniques, SfM photogrammetry has great potential to be applied in harsh high-mountain environment. Here point clouds and derived by-products (DEM's, orthoimages, Virtual-Reality models) are needed to document surface morphology and to investigate dynamic processes such as landslides, avalanches, river and soil erosion, glacier retreat. On the other hand, from both the literature and the direct experience of the authors, there are some technical issues that still deserve thorough investigations. The paper would like to address some open problems and suggest solutions, in particular on regards of the photogrammetric network design, the strategy for georeferencing the final products, and for their comparison within time. The discussion is documented with some examples, mainly from surveying campaigns at the Forni Glacier in Italian Alps.
\end{abstract}

\section{INTRODUCTION}

Three-dimensional surveying plays today an important role in the analysis of the mountain environment, where different processes need geometric models to be thoroughly studied. In some cases, such 3D point clouds are required for investigating some conditions at a specific epoch, but often repeated surveys are necessary for monitoring evolving processes within time. Many scientific and engineering domains maybe interested by the use of point clouds at different degree of resolution, or digital elevation models (DEM's) obtained after interpolation at nodes of a regular raster grid. In Geomorphology, Engineering Geology, Glaciology, Mountain Hydrology, point clouds or DEM's of large portions of the topographic surface are needed for the assessment of stability conditions and for monitoring landslides, avalanches, river and soil erosion, glacier retreat. and the like. In ecology and biology, small plots are investigated to detect the relationship between soil geometry and conditions with vegetation and animal life (Niederheiser et al., 2016). But also Anthropological and Human Sciences as well as Cultural Heritage $(\mathrm{CH})$ documentation may be interested by studying specific structures and human settlements in the mountain environment (see, for example, Pichler et al., 2013).
An interesting point-of-view related to the exploitation of 3-D point clouds regards the reconstruction of a virtual environment where measurements and analyses may be accomplished instead of working in the field. This is the case, for example, of Virtual Geoscience (Jaboyedoff et al., 2015; Buckley et al., 2017).

Due to the large variability in scale, required accuracy and resolution, as well as the extension of $3 \mathrm{D}$ point clouds, a large number of techniques may be applied for their surveying and generation. Some applications may be effectively afforded on the basis of high-/very high-resolution satellite images (Barbarella et al., 2017). Thanks to the continuous growth of the available sensors and their improving features (e.g., in term of ground sample distance - GSD - and time resolution), this category of satellite optical imagery offers the opportunity to obtain 3D point clouds on the basis of photogrammetric techniques for dense surface matching. Resolution and accuracy at submeter level may be reached. Other advantages are given by the reduced field work, the wide covered region and the opportunity to obtain archive images to be used for retrospective analyses. It is worth to mention that also satellite images at medium resolution maybe used for static and

${ }^{1}$ Corresponding author 
dynamic modelling of some phenomena in remote geographic location or before the era of high-resolution imagery. Examples of such applications are extraterrestrial mapping (see, e.g., Scaioni et al., 2018a) or Antarctic research (see Li et al., 2016). Last but not least, microwave remote sensing may provide DEM's covering entire regions or the whole globe, as in the case of SRTM (Bertiér et al., 2006) global model. Both satellite radar altimetry (Łyszkowicz \& Bernatowicz, 2017) and interferometric processing of Synthetic Aperture Radar (SAR) data from satellite (e.g., Zink et al., 2017) and aircrafts (e.g., INTERMAP, 2018) are used. Of course, the resolution of these DEM's is lower, from a few metres to decades of metres.

The immediate step after the use of satellite data is given by standard airborne sensors, mainly encompassing aerial photogrammetry (Pepe et al., 2018) and airborne LiDAR (Shan \& Toth, 2009). While increased performances maybe achieved, these consolidated techniques involve the organization of a tailored flight mission in the case new data acquisition is necessary. The cost of these operations may depend on many factors, but in general it is difficult to afford in the case of small projects or limited budget.

The development and diffusion of photogrammetric UAV/UAS (Unmanned Aerial Vehicles/Systems) has dramatically mitigated the big impact of manned airborne mission for imaging/scanning purpose (Colomina \& Molina, 2015). Thanks to the possible low flying height, drones may collect images of the topographic surface at high resolution, while the acquisition of laser scanning data is still limited to a small number of unmanned aircrafts (Brede et al., 2017).

The last paradigm for 3D point cloud acquisition concerns terrestrial (or ground-based) techniques, mainly terrestrial laser scanning (TLS) and close-range photogrammetry. In the former case, TLS allows the direct acquisition of point clouds to describe the topographic surface of the surveyed area. Unless a few special applications, in the mountain environment the distances between the sensor standpoints and the region of interest maybe very large, spanning up to a few kilometres (see, e.g., Fey et al., 2017). This feature calls for the use of verylong-range laser scanners based on the Time-of-Flight measurement principle, see Heritage \& Large (2009). Using such a kind of instruments, which may offer an adequate operational range, an accuracy in the order of decimeters can be achieved. On the other side, this category of instruments are still cumbersome and require heavy energy supply, so that they operational use in high-mountain regions may be very difficult.

As effective alternative to TLS, Structure-from-Motion (SfM) photogrammetry (Westoby et al., 2014; Eltner et al., 2016; Granshaw, 2018) may provide dense point clouds (Remondino et al., 2014) on the merely basis of images collected with standard digital cameras. SfM is independent from the a priori knowledge of the approximate camera poses and may work with any types of photogrammetric network geometry, provided that sufficient multiple image overlaps, adequate baselines, and photo texture are given. Ground control points (GCP's) are necessary for geo-referencing in a given datum, though alternative solutions will be discussed in Subsection 3.3. In strict meaning, the term 'SfM' refers only to the automatic procedure for computing the $\mathrm{EO}$ of a sequence (or block) of images by concatenating small groups of images that have been registered using Feature-Based Matching (FBM). After Westoby et al. (2013), in the Geosciences this term often means the whole automatic process to obtain the image-based 3D reconstruction including dense surface matching as well.

This paper would like to discuss some technical issues related to the application of SfM photogrammetry in highmountain projects. Indeed, from the experience of the authors and the literature, it seems clear that some aspects need to be better investigated and addressed, in particular the ones regarding the photogrammetric network design (Sect. 2) and the strategy for georeferencing the final products (Sect. 3). This latest problem becomes even more relevant when outputs from SfM have to be compared within time. The discussion is documented with some examples, mainly from surveying campaigns at the Forni Glacier in Italian Alps. Details about this case study are not reported here, but readers may refer to Fugazza et al. (2018).

\section{PHOTOGRAMMETRIC NETWORK}

\subsection{Data acquisition design and planning}

The acquisition of images in high-mountain environment may usually suffer from many factors that limit the operations and constrain the geometry of the photogrammetric network to acquire (Dall'Asta et al., 2015). With this term, the camera stations and the resulting connections between the images in terms of corresponding tie points (TPs) to compute image exterior orientation (EO) in a SfM fashion (Hartmann et al., 2016) and for successive $3 D$ reconstruction through dense matching is intended (Barazzetti et al., 2009). The main issues are related to the complex surface topography that it typical of mountain areas, limiting the organization of the data acquisition campaign on one side, and making complex the collection of a suitable block geometry on the other. In addition, the use of UAV's, which may be an alternative to overcome many of these problems, could result in some practical issues. UAV's are more difficult to operate in such environments because of the rare air requiring more energy consumption and then limiting the flight endurance. Other issues concern the frequent windy and bad weather conditions, the presence of obstacle like flanks of valleys, and the difficulty of finding good taking off/landing places. In some applications such as glacier, landslide, or river erosion monitoring, the surface continuously changes within short time. This requires to partially or even completely re-plan the network geometry at any campaigns. Under a more technical point-of-view, typical photogrammetric aspects that should be considered are: (i) the required precision and final point density, which mainly attain at the selection of a proper range of photo-scales (see Luhmann et al., 2014; Eltner et al., 2016); (ii) the sufficient multi-stereo coverage to guarantee the effective application of SfM and dense-matching techniques (Wenzel et al., 2013) and to produce a suitable local redundancy of photogrammetric observations (Kraus, 1997). This property, today often forgotten, gives the opportunity to rise up the efficiency of data snooping techniques (Förstner \& Wrobel, 2016) that are implemented in bundle block adjustment (BBA) procedures (Luhmann et al., 2014) that are used to 
estimate the EO. Finally, the methodology adopted to define the geodetic datum (see Sect. 3) generally influences the design of the photogrammetric network.

2.1.1 Terrestrial blocks. Three main Categories of block geometries are used to deal with the large majority of applications, depending on the size and the shape of the region to be surveyed:

1. Surfaces with an almost flat elongated shape (horizontal, vertical, sub-vertical) that may refer to a main reference plane, but also presenting some occlusions which cannot be imaged by parallel photos only;

2. Large surfaces with inhomogeneous characteristics; and

3. Compound surfaces that could be split into more subregions featuring properties from Categories 1 or 2 .

Other surface shapes are not so common in the considered environment, for example courtyard-like sites typical of architectural photogrammetry, where photos should be captured from inside looking towards the outer surfaces. Circular blocks to depict full-form 3D objects or to focus on small plots are seldom used, see Kääb et al. (2014) and Niederheiser et al. (2016). In the following an approach to deal with different Categories of surfaces are discussed.

In blocks belonging to Category 1 the design of the photogrammetric network should entail:

1. A main image sequence made up of parallel photos (see Fig. 1a) with large overlap (75-85\%) is captured to follow the shape of the surface at average distance $D_{p}$. This is selected to guarantee the required precision and resolution. The former may be roughly estimated using formulas for the stereo or multi-view cases (Luhmann et al., 2014). The latter depends on the average GSD. Considering that up-to-date techniques for dense matching work in a pixelwise manner, the obtainable point resolution can be evaluated on the basis of the adopted algorithm. If necessary and possible, two or more parallel sequence (at different heights, for instance) could be collected;

2. Convergent images are integrated into the main image sequence by rotating the camera of approximately $30^{\circ}-45^{\circ}$ from the strip direction, in forward and backward directions (see Fig. 1a). As a rule of thumb, the acquisition of convergent images may alternatively occur in correspondence of "even" camera stand-points, considering a regular progressive numbering of the main sequence;

3. Rolled $90^{\circ}$ images have also to be captured from the same stand-points of the main sequence (see Fig. 1a). This subset is needed only in the case the camera is not precalibrated, and camera calibration has to be computed within the BBA for estimating EO, see Barazzetti et al. (2011). As an empirical rule, in blocks made up of a number of photos smaller than $N_{i m}=30$, four rolled photos should be minimally included; when $N_{i m}>30$, one rolled photos every 8-10 acquired photos should be taken; and

4. In presence of relevant occlusions, one or more specific sub-blocks with orientation aiming at filling gaps in image coverage have to be included (see Fig. 1b).

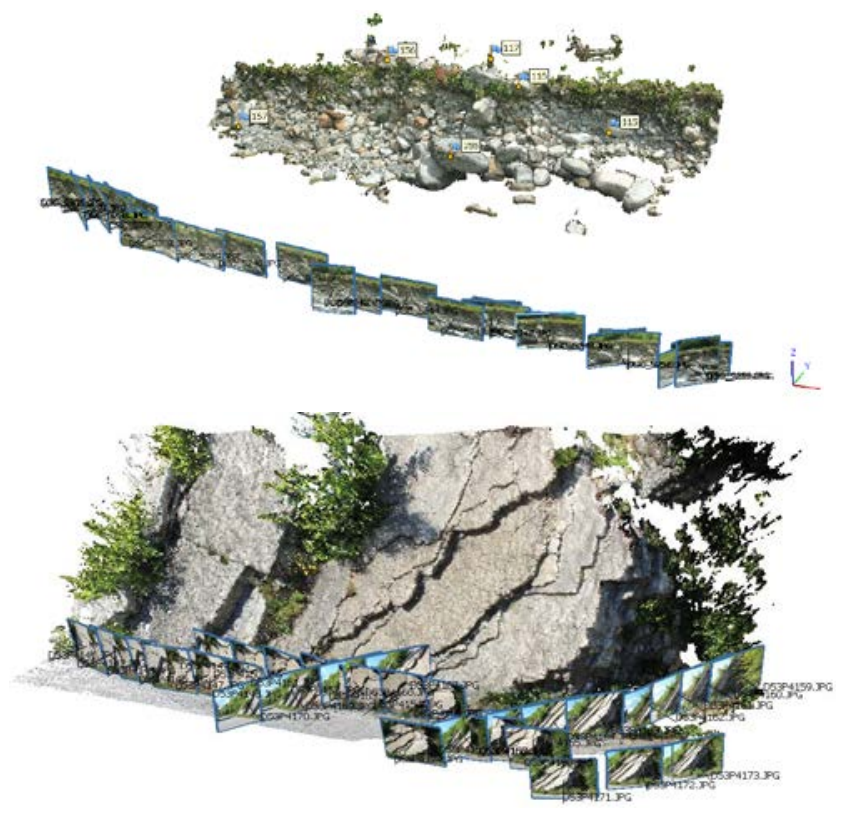

Figure 1. Two typical configurations of terrestrial photogrammetric networks in Cat. 1. In the upper part (a), a block configuration including a main strip, a few $90^{\circ}$ rolled photos, and convergent photos. In the lower part (b), the block consists of a main strip and two other diagonal strips to fill occlusions.

Category 2 comprehends those surfaces featuring complex shapes, which may be also located in areas difficult to be accessed. This is the typical case of Alpine glaciers, see, e.g., Piermattei et al., 2015, 2016, and Scaioni et al., 2017. In such an environment, image acquisition is much more involved, being difficult - if not impossible - to establish a predefined network geometry as in Cat. 1. However, some general criteria are worth to be kept in mind:

1. Since the local topography may obstacle image acquisition, all those accessible areas around the target surface should be exploited to set up camera stations. The desired range of photo scales should be respected, even though this goal may be more difficult to achieve than in Cat. 1. In Scaioni et al. (2017a) a discussion is reported whether is better to acquire more images with shorter baselines, or less images with longer baselines and a more regular geometry. The proposed solution is to capture a larger number of images with shorter baselines, since the number of points in the final point cloud is proportional to the number of employed image;

2. In this case it may be difficult to distinguish between "parallel" and "convergent" images, since the surface shape may be more irregular (see Fig. 2). Anyway, it should be checked that the same portions of the surface are visible in multiple camera stations with a good geometry of intersecting rays; 


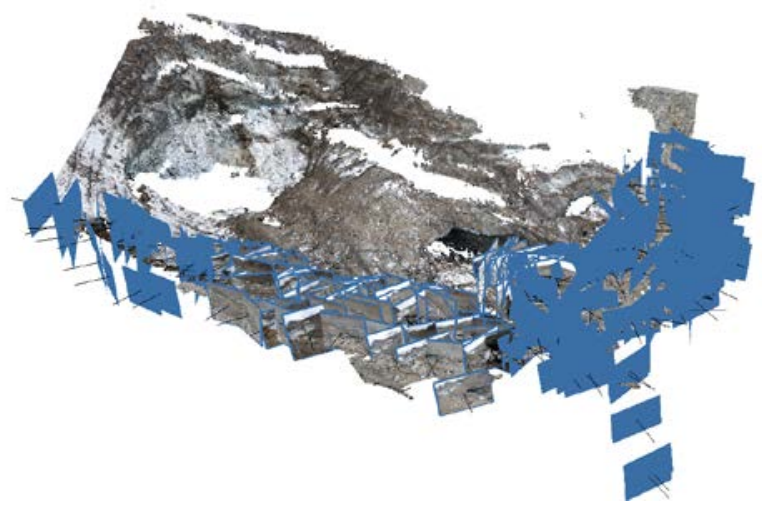

Figure 2. Example of a block of images in Cat. 2, capturing the terminus of the Forni Glacier (Italian Alps).

3. Rolled $90^{\circ}$ images have to be captured in the case the camera is not pre-calibrated. Approximately, one rolled photo should be captured every10 acquired photos;

4. In presence of obstacles or occlusions, additional images should be included in the network to allow the reconstruction of missing parts; and

5. If possible, GCP's or other solutions for geo-referencing (see Subsect. 3.3) could be used be split the whole block in more independent sub-blocks.

2.1.2 UAV blocks. In this case, the geometry of the photogrammetric network is completely different than in the previous case. Readers are addressed to the specific literature, in particular to O’Connor et al. (2017) and Pepe et al. (2018).

2.1.3 Mixed blocks. The chance to set up photogrammetric projects including either terrestrial and UAV blocks of images may help dealing with those surfaces that concurrently feature both horizontal and vertical/sub-vertical exposure. Since these types of blocks are acquired with different cameras and photogrammetric networks, both projects should be preferably organized independently. The fusion of resulting point clouds is obtained by exploiting GCPS's, whose coordinates are measured w.r.t. the same reference system (see Sect. 3). In Figure 3, an example of point cloud merging both terrestrial (in red) and UAV data of the Forni Glacier is shown. Both photogrammetric projects have been georeferenced using GCP's. More detail about the data fusion process can be found in Fugazza et al. (2018).

\subsection{Simulating theoretical accuracy}

In the case of terrestrial and UAV blocks, some methodologies have been recently published to evaluate the precision of $3 \mathrm{D}$ coordinates that can be achieved after dense matching, given a specific photogrammetric network, see Dall'Asta et al. (2015) and James et al. (2017), respectively. On the other hand, these methods require the knowledge of the surface shape beforehand. Thus, their application is viable only in the case of objects whose shape does not dramatically change between surveying campaigns.

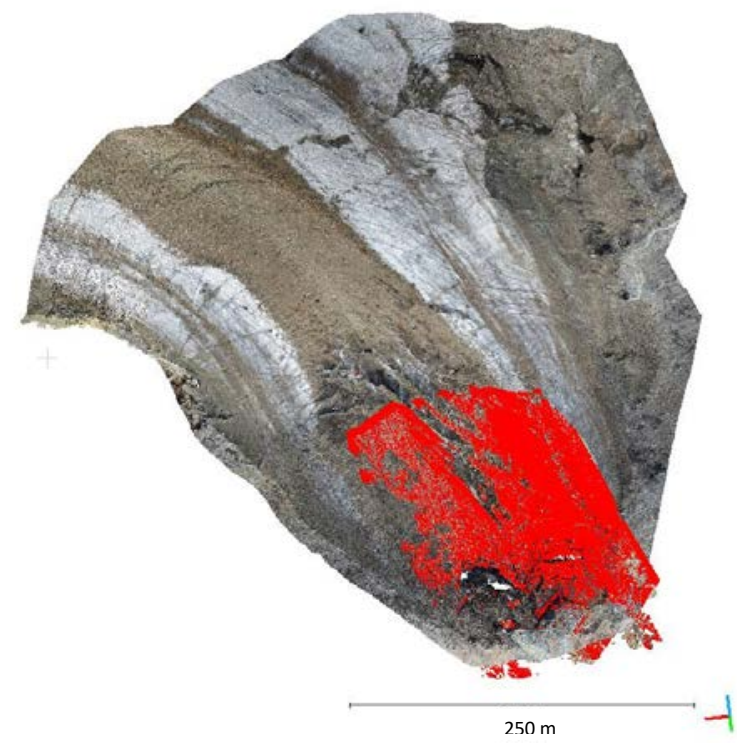

Figure 3. Point cloud of the Forni Glacier composed by data obtained from UAV (in real colour) and terrestrial photogrammetry (in red).

\section{GEOREFERENCING AND REGISTRATION}

\subsection{Georeferencing single-epoch projects}

In the most applications, point clouds obtained from SfM photogrammetry (or from other techniques) need to be georeferenced in a local topographic datum (i.e., with the $z$ direction aligned to the local plumb line and an arbitrary orientation of horizontal axes) or in a geodetic/mapping datum. This second option is necessary when a data set has to be overlap to other existing geospatial data, or in the case absolute orientation is needed to study some physical processes (for example, the exposition to sun-lighting of slopes). While a local topographic datum may be established using a theodolite (Schofield \& Breach, 2007), GNSS techniques (HofmannWellenhof et al., 2008) may provide a direct solution for georeferencing in a geodetic/mapping datum.

In general, GNSS positioning can be used to establish a local reference network. The benchmarks of this network can be adopted as starting point for local measurement operations based on "master-rover" RTK techniques or geodetic surveying. In the case a GNSS real-time positioning service is available and the internet network can be accessed, photogrammetric GCP's may be directly measured using a GNSS geodetic receiver (see Fig. 4a), without the need of a local reference network. This solution may work well with UAV photogrammetric projects, where in general markers are placed on the ground surface to serve as GCP's. When photos are captured from ground-based stations, markers might have to be put on vertical surfaces in order to be clearly visible in the images (see Fig. 4b). This requirement involves the use of a theodolite, to be set up and oriented over a couple of points belonging to the local reference network. 


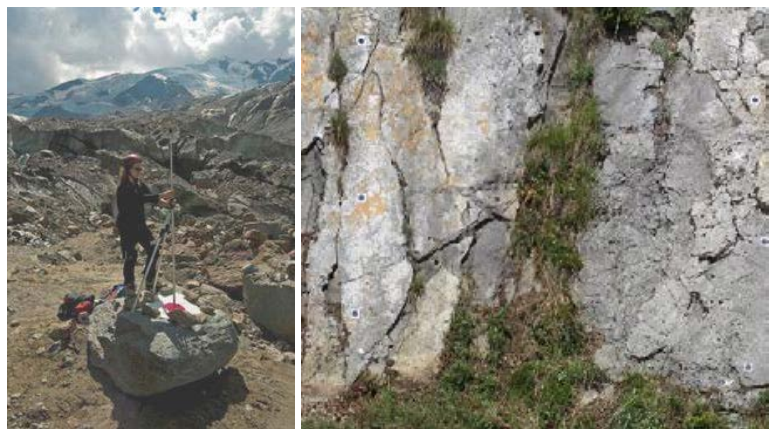

Figure 4. GCP measurement: on the left (a) an example of a marker put on a rock for UAV photogrammetry; on the right (b) some markers put on a rock face for terrestrial photogrammetry.

\subsection{Georeferencing multi-epoch projects}

The problem is more involved in the case multi-temporal data acquisition campaigns have to be repeated for monitoring purpose. In this case the stability of the reference datum is crucial to compare all data sets. The classical solution is to define some stable benchmarks, which can be used within either a local topographic datum and a geodetic/mapping datum.

Even though this may seem a trivial consideration, benchmarks should be (a) placed in stable, protected and accessible locations; (b) not far away from the area where markers have to be measured to limit error propagation; and (c) well documented in order to be retrieved at each measurement epoch (a low-cost GNSS can be employed to this purpose).

The alternative solution is to use GNSS positioning to reestablish the local reference network at any epochs, as suggested in Barbarella et al. (2015; 2017). Depending on the required accuracy of the local datum, a static GNSS network or a GNSS positioning service - if available and providing sufficient precision - could be used. In both cases, attention should be put to maintain the same network geometry when repeating the GNSS measurements at different epochs.

The transformation from ellipsoidal elevation obtained from GNSS to orthometric height is another important point, because the latter is necessary to study physical processes and to compare the derived products to existing maps and DEM's. Even tough accurate regional geoid models are available in several countries, their accuracy in mountain areas is in general less precise. Consequently, if the investigated area has a limited extension (less than few square kilometres) a common vertical shift should be adopted to transform ellipsoidal elevations into orthometric heights.

\subsection{Alternative solutions for ground constrain}

GCP's represent the standard solution for georeferencing photogrammetric blocks. However, their set up may be complex or impossible in the mountain environment, due to the local surface morphology, the presence of possible risks for operators, and the limited time for surveying operations. In addition, in multi-epoch projects, very often markers cannot be left in permanent way and need re-positioning before each photogrammetric campaign. Some alternative solutions are available and may be considered in applications for georeferencing individual blocks surveyed at each epoch (Par. 3.3.1 and Par. 3.3.2). Of course, the discussion reported in the previous section about the establishment of a local reference network still holds in both the cases analyzed in the following. In the case of multi-temporal surveys, an option is to obtain the geo-referencing of the initial epoch, and then to co-register all data coming from successive campaigns (see Subsect. 3.4).

3.3.1 PhotoGPS and PhotoTS. Forlani et al. (2014, 2015) proposed and evaluated a solution based on the direct measurement of camera position using a GNSS geodetic receiver, whose antenna is rigidly connected to the camera body (PhotoGPS). After independent camera calibration and determination of the eccentricity vector $(e)$ between the phase centre of the antenna and the perspective centre of the camera, the antenna positions recorded during image acquisition using an RTK approach could be included as constraints in the BBA. This method was used in two projects concerning the surface reconstruction of a glacier and a rock slope. It is interesting to notice that residuals on the antenna positions after BBA were less than $5 \mathrm{~cm}$. This value is much inferior to typical residuals on GCP's adopted in terrestrial photogrammetric projects in high-mountain, that may result in the order of few decimeters (see Piermattei et al., 2015, 2016; Fugazza et al., 2018).

In a way emulating PhotoGPS, a solution based on a topographic reflector and a digital camera constrained to a frame mounted over a topographic tripod has been developed (PhotoTS). The tripod is equipped with a tribrach that can be levelled. Thanks to the procedure presented in Barazzetti et al. (2013) for the alignment of the camera to the frame (and then to the reflector), the horizontal component $e_{H}$ of the eccentricity vector $e$ can be eliminated, while the vertical component $e_{V}$ is measured with ease. When the camera is used in the field to capture the images for photogrammetric reconstruction, some stations are set up on the topographic tripod, and the coordinates of the camera perspective centres are measured with a theodolite. The uncertainty in the determination of $e_{H}$ and $e_{V}$ is much lower than the coordinate measurement precision by the theodolite. Alternatively, the topographic reflector may be replaced by a GNSS antenna. When introduced in the BBA, the coordinates of perspective centres corresponding to those camera stations measured from the theodolite are used to constrain the datum. Additional free camera poses may be included, to be link to the previous ones thanks to TP's extracted in SfM. This solution, which does not entail the estimate of $e$, is prone to be used by people with less experience in photogrammetry and within common software packages for SfM. In the case a rigorous BBA is implemented, where known perspective centers' coordinates may be treated as stochastic observations, these can be used to correct internal block deformations. While the ground constrain is used only to apply a rigid-body transformation to the resulting point cloud, the only results will be the global georeferencing of the photogrammetric outputs. In PhotoTS (and PhotoGPS) a reliable pre-calibration of the adopted camera is necessary (see Zhang et al., 2018). 
3.3.2 UAV with GNSS-RTK positioning. In the case a UAV project is needed, the employ of a GNSS-RTK sensor on-board may directly provide a sufficient accuracy for the EO parameters. Dall'Asta et al. (2016) report about RMSE evaluated with respect of independent check points in the order of $4 \mathrm{~cm}$ and $7 \mathrm{~cm}$ for horizontal position and elevation, respectively.

\subsection{Registration of different data sets}

In some cases, the accurate georeferencing of multiple data sets to be compared is not achieved for all of them. This might be also the situation when data sets from other projects or with a different geodetic datum have to be considered. Two approaches to cope with these conditions are discussed in the following. The first may be applied when only final point clouds or DEM's are available. The second require the availability of images to be processed.

3.4.1 Point cloud or DEM registration. In the case two point clouds have to be registered, a preliminary alignment has to be carried out to roughly transform one in the reference system of the other, assumed as reference. Then a method to refine the registration should be applied. Here the case of a DEM, that maybe considered as a $2.5 \mathrm{D}$ data set, should be distinguished from a full 3D point cloud. In the case of DEM comparison, a consolidated method is due to Berthier et al. (2007), which does minimize the vertical differences on common stable areas by shifting one surface w.r.t. the other, and then subtracts the residual vertical bias. In the case of 3D point clouds, the fine alignment may be generally computed using ICP-based methods (see Pomerleau et al., 2013). Even in this case, when changes have occurred between data collection times, the identification of stable areas should be done to be used for fine registration. Wujanz et al. (2016) introduced a method for the automatic selection of stable areas. Once both surfaces are aligned, deformations and changes can be detected using different techniques, as reported in Lague et al. (2013) and Lindenbergh \& Pietrzyk (2015).

3.4.2 Feature-Based Matching registration. In the case no other solutions are possible but the original photogrammetric photos are available, another approach to co-registration is given by using images depicting common areas, but taken at different epochs. Assuming one photogrammetric block as reference (Block 1), all its images are oriented using SfM. The second block to be registered (Block 2) is independently oriented with the same method. During this step, cameras are also self-calibrated within the BBA to compute the EO, if not pre-calibrated. This processing stage is also used to solve for specific problems with the orientation of each block. For instance, sometimes SfM may not handle the extraction of enough TP's to connect all the images. While the availability of GCP's may help overcome such situations, if these are pending other solutions should be found. For example, subblocks can be merged by co-registering the final point clouds obtained with dense matching. Once all the images of Blocks 1 and 2 have been oriented, some images (SubBlock 2) from Block 2 that cover a quite stable area also depicted in "Block 1 " have to be selected. The number of chosen images should be sufficient to extract manifold TP's with a good geometric distribution on the overall blocks. Images from SubBlock 2 are joined to Block 1 Then the application of SfM should yield the EO of these images in the same reference system of Block 1. Thanks to the robustness of FBM implemented in SfM and the presence of multi-ray TP's, even in the case of partial changes of texture and surface geometry, a reliable EO of the images belonging to both Block 1 and SubBlock 2 may be achieved. Since now SubBlock 2 is shared with both Blocks 1 and 2, points identified in it can be computed in their reference systems. These points can be used for computing a 3D similarity transformation to register both data sets.

The method described in this paragraph has been applied to co-register two blocks captured on the Forni Glacier. As widely described in a previous paper (Scaioni et al., 2018b) a block consisted of 323 images captured from ground-based stations was oriented using SfM implemented in Agisoft Photoscan $^{\circledR} \quad$ Professional ver. 1.4.0 (www.agisoft.com). Unfortunately, since during data acquisition no ground control could be measured, the only possibility was to co-register this block with respect to a previous block collected during 2016 (see also Fugazza et al., 2018). Neither the ICP registration after the computation of dense point clouds with dense matching, nor the manual measurement of corresponding points between both data sets of images, could work. In fact, several abrupt changes occurred because of large collapses in the terminus area of the glacier. Then 47 images from the "2017” Block depicting some stable areas have been added to the terrestrial block captured on 2016. This new block has been oriented again using SfM. Five points have been manually measured on the set of 'shared' images. Their object coordinates obtained from spatial intersection have been used as GCP's in “2017” Block. A RMSE of residuals on GCP's equal to $33 \mathrm{~cm}$ has been found. After merging, the dense surface matching has been applied to reconstruct the point cloud modelling the glacier surface on 2017.

\section{DISCUSSION AND CONCLUSION}

Structure from Motion (SfM) photogrammetry is fully mature to be operated in harsh and complex environment such as highmountain areas. By using ground-based and UAV-based images, this technique has the potential to provide detailed and sufficiently accurate point clouds to investigated static and dynamic problems. On the other hand, notwithstanding the high degree of automation, the apparent simplicity of usage and the availability of powerful low-cost and open-source software packages, its effective application requires a thorough knowledge of principle that stand behind. As concluded in Carboneau \& Dietrich (2016), SfM obeys to the basic laws of Photogrammetry, that should be known and kept in mind when planning and developing applications.

This conclusion underlines how much the education and training of photogrammetry in the Alpine environment is important. Beyond the role of the academy, specific initiatives have been carried on, such as the "ISPRS Summer School on Close-Range Sensing Techniques in Alpine Terrain” (Rutzinger et al., 2016, 2018), the development of specific active-learning tools (Scaioni, 2017b, 2018c), and the distribution of relevant teaching material and data sets. The last task is just the main goal of one of funded projects in the "ISPRS Education and Capacity Building Initiatives 2018," 
namely "Spreading out the Knowledge from ISPRS Educational Events using a Dissemination Internet Platform.”

\section{Acknowledgements}

This study was partially funded by DARAS (Presidency of the Council of the Italian Government). The authors acknowledge the Central Scientific Committee of CAI (Italian Alpine Club) and Levissima San Pellegrino S.P.A. for funding the UAV quadcopter. The authors also thank Stelvio Park Authority for the logistic support and for permitting the UAV surveys and IIT Regione Lombardia. The authors would also like to acknowledge all those colleagues, students and friends who helped within different stages of field operations. This paper is dedicated to our colleague Francesco Rota Nodari (Politecnico di Milano, Italy), who gave a great contribution to the Alpine exploration and the scientific investigation of high-mountain environment.

\section{REFERENCES}

\section{References from books:}

Förstner, W., Wrobel, B.P., 2016. Photogrammetric Computer Vision. Springer-Verlag, Berlin Heidelberg, Germany.

Heritage, G.L. and A.R.G. Large, 2009. Laser Scanning for the Environmental Sciences. John Wiley \& Sons, Chichester, U.K., 302 pages.

Hofmann-Wellenhof, B., Lichtenegger, H., Wasle, E., 2008. GNSS GPS, GLONASS, Galileo \& more. Springer Verlag.

Kraus, K., 1997. Photogrammetry - Vol. 2. Dümmler Verlag, Bonn, Germany.

Luhmann, T., Robson, S., Kyle, S., Boehm. J.,2014. Close Range Photogrammetry: 3D Imaging Techniques - 2nd Edition. Walter De Gruyter Inc., Germany, 684 pages.

Shan, J. and C.K. Toth, 2009. Topographic Laser Scanning and Ranging. Principles and Processing. Taylor and Francis Group, Boca Raton, FL-USA.

Schofield, W., Breach, M. 2007. Engineering Surveying - 6th Edition. Butterworth-Heinemann

Zhang, X., Qiao, G., Scaioni, M., 2018. Evaluation of 3D Reconstruction Accuracy in the Case of Stereo Camera-Pose Configuration. In: R. Cefalo, J.B. Zielinski, M. Barbarella (Ed.’s), New Advanced GNSS and 3D Spatial Techniques, Lecture Notes in Geoinformation and Cartography, pp. 177-187, DOI: 10.1007/978-3319-56218-6_14.

\section{References from journals:}

Barazzetti L., Previtali, M., Scaioni, M., 2013. Stitching and Processing Gnomonic Projections for Close-Range Photogrammetry. Photogramm. Eng. Remote Sens., 79(6): 573-582.

Barbarella, M., Fiani, M., Lugli, A., 2015. Multi-temporal Terrestrial Laser Scanning Survey of a Landslide. In: M. Scaioni (Ed.), Modern Technologies for Landslide Monitoring and Prediction, Springer Natural Hazards, Berlin Heidelberg (Germany), DOI: 10.1007/978-3662-45931-7_5.

Barbarella, M., Fiani, M., Lugli, A., 2017. Uncertainty in terrestrial laser scanner surveys of landslides. Remote Sensing, 9(2), paper No. 113.

Barbarella, M., Fiani, M., Zollo, C., 2017. Assessment of DEM derived from very high-resolution stereo satellite imagery for geomorphometric analysis. European Journal of Remote Sensing, 50(1): 534-549, DOI: 10.1080/22797254.2017. 1372084.
Berthier, E., Arnaud, Y., Vincent, C., Rémy, F., 2006. Biases of SRTM in high-mountain areas: Implications for the monitoring of glacier volume changes. Geophysical Research Letters, 33(8), paper No. L08502.

Berthier, E., Arnaud, Y., Kumar, R., Ahmad, S., Wagnon, P., Chevallier, P., 2007. Remote sensing estimates of glacier mass balance in the Himachal Pradesh (Western Himalaya, India). Remote Sensing of Environment, 108: 327-338.

Brede, B., Lau, A., Bartholomeus, H.M., Kooistra, L., 2017 Comparing RIEGL RiCOPTER UAV LiDAR Derived Canopy Height and DBH with Terrestrial LiDAR. Sensors, 17, paper No. 2371.

Buckley, S.J., Kurz, T.H., Chandler, J.H., Jaboyedoff, M., Derron, M.H., 2017. Virtual Geoscience Conference 2016: where Geomatics meets Geoscience. The Photogrammetric Record, 32(160): 346-349.

Carboneau, P.E., Dietrich, J.T., 2016. Cost-effective non-metric photogrammetry from consumer-grade sUAS: implications for direct georeferencing of structure from motion photogrammetry. Earth Surf. Process. Landforms, 42(3): 473-486.

Colomina, I., Molina, P., 2014. Unmanned aerial systems for photogrammetry and remote sensing: A review. ISPRS Journal of Photogrammetry and Remote Sensing, 92: 79-97.

Dall'Asta, E., Thoeni, K., Santise, M., Forlani, G., Giacomini, A., Roncella, R., 2015. Network Design and Quality Checks in Automatic Orientation of Close-Range Photogrammetric Blocks. Sensors, 17: 7985-8008.

Dall'Asta, E., Delaloye, R., Diotri, F., Forlani, G., Fornari, M., Morra di Cella, U., Pogliotti, P., Roncella, R., Santise, M., 2016. Unmanned Aerial Systems and DSM matching for rock glacier monitoring. ISPRS Journal of Photogrammetry and Remote Sensing, 127: 102-114.

Eltner, A., Kaiser, A., Castillo, C., Rock, G., Neugirg, F., Abellán, A., 2015. Image-based surface reconstruction in geomorphometry - merits, limits and developments. Earth Surface Dynamics, 4: 359-389.

Fey, C., Wichmann, V., Zangerl, C., 2017. Reconstructing the evolution of a deap seated rockslide (Marzell) and its response to glacial retreat based on historic and remote sensing data. Geomorphology, 298: 72-85.

Forlani, G., Pinto, L., Roncella, R., Pagliari, D., 2014. Terrestrial photogrammetry without ground control points. Earth Science Informatics, 7: 71-81.

Forlani, G., Roncella, R., Diotri, F., 2015. Production of highresolution digital terrain models in mountain regions to support riskassessment. Geomatics, Natural Hazards and Risk, 6(5-7): 379-397.

Fugazza, D., Scaioni, M., Corti, M., D’Agata, C., Azzoni, R.S., Cernuschi, C., Smiraglia, C., Diolaiuti, G., 2017. Combination of UAV and terrestrial photogrammetry to assess rapid glacier evolution and conditions of glacier hazards. Natural Hazards Earth System Science, 18: 1055-1071, DOI: 10.5194/nhess-18-1055-2018.

Granshaw, S.I., 2018. Editorial: Structure from Motion. Origins and Originality. The Photogrammetric Record, 33(161): 6-10.

Jaboyedoff, M., Derron, M.-H., Buckley, S.J., Scaioni, M., 2015. Introduction to Vertical Geology thematic issue. European Journal of Remote Sensing, Vol. 48: 479-487, DOI: 10.5721/EuJRS20154827.

James, M.R., Robson, S., Smith, M.W., 2017. 3-D uncertainty-based topographic change detection with structure-from-motion photogrammetry: precision maps fro ground control and directly georeferenced surveys. Earth Surface Processing and Landforms, 42: 1769-1788.

Kääb, A., Girod, L., Berthling, I., 2014. Surface kinematics of periglacial sorted circles using structure-from-motion technology. The Cryosphere, 8: 1041-1056.

Hartmann, W., Havlena, M., Schindler, K., 2016. Recent developments in large-scale tie-point matching. ISPRS Journal of Photogrammetry and Remote Sensing, 115: 47-62. 
Lague, D., Brodu, N., Leroux, J., 2013. Accurate 3D comparison of complex topography with terrestrial laser scanner: application to the Rangitikei canyon (N-Z). ISPRS J. Photogramm. Remote Sens., 82: 1026.

Lindenbergh, R., Pietrzyk, P., 2015. Change detection and deformation analysis using static. Applied Geomatics, 7(2): 65-74.

Luhmann, T., Fraser, C., Maas, H.-G., 2016. Sensor modelling and camera calibration for close-range photogrammetry. ISPRS J. Photogramm. Remote Sens., 115: 37-46.

Łyszkowicz, A.B., Bernatowicz, A., 2017. Current state of the art of satellite altimetry. Geodesy and Cartography, 66(2): 259-270.

O’Connor, J., Smith, M.J. James, M.R., 2017. Cameras and settings for aerial surveys in the geosciences: optimising image data. Progress in Physical Geography, 41(3): 325-344, DOI: 10.1177/0309133317703092.

Pepe, M., Fregonese, L., Scaioni, M., 2018. Planning Airborne Photogrammetry and Remote-Sensing Missions with Modern Platforms and Sensors. European Journal of Remote Sensing, available online at DOI: 10.1080/22797254.2018.1444945.

Pichler, T., Nicolussi, K., Goldenberg, G., Hanke, K., Kovács, K., Thurner, A., 2013. Charcoal from a prehistoric copper mine in the Austrian Alps: Dendrochronological and dendrological data, demand for wood and forest utilization. Journal of Archaeological Science, 40(2): 992-1002.

Pomerleau, F., Colas, F., Siegwart, R., Magnenat, S., 2013. Comparing ICP variants on real-world data sets. Autonomous Robots, 34(3): 133148.

Remondino, F., Spera, M. G., Nocerino, E., Menna, F., Nex, F., 2014. State of the art in high density image matching. The Photogrammetric Record, 29(146): 144-166.

Scaioni, M., Yordanov, V., Brunetti, M.T., Melis, M.T., Zinzi, A., Kang, Z., Giommi, P., 2018a. Recognition of landslides in lunar impact craters. European Journal of Remote Sensing, 51(1): 47-61, DOI: 10.1080/22797254.2017.1401908.

Westoby, M.J., Brasington, J., Glasser, N.F., Hambrey, M.J., Reynolds, J.M., 2012. "Structure-from-Motion" Photogrammetry: A low-cost, effective tool for geoscience applications. Geomorphology, 179: 300314.

Wujanz, D., Krueger, D., Neitzel, F., 2017. Identification of Stable Areas in Unreferenced Laser Scans for Deformation Measurement. The Photogrammetric Record, 31(155): 261-280.

Zink, M., and other 7, 2017. The global TanDEM-X DEM - A unique data set. In: Proc. IGARRS 2017, Fort Worth, TX, USA, 23-28 Jul, available at DOI: 10.1109/IGARSS.2017.8127099.

\section{References from Other Literature:}

Barazzetti L., Remondino, F., Scaioni, M., 2009. Combined use of Photogrammetric and Computer Vision techniques for fully automated and accurate 3D modeling of terrestrial objects. In: Proc. of SPIE, Vol. 7447.

Barazzetti L., Mussio L., Remondino, F., Scaioni M., 2011. Targetless camera calibration. Int. Arch. Photogramm. Remote Sens. Spatial Inf. Sci., 38-5/W16, 8 pages.

Cogliati, M., Tonelli, E., Battaglia, D., Scaioni, M., 2017. Extraction of DEMs and Orthoimages from Archive Aerial Imagery to Support Project Planning in Civil Engineering. ISPRS Ann. Photogramm. Remote Sens. Spatial Inf. Sci., IV(5/W1): 9-16, DOI: 10.5194/isprsannals-IV-5-W1-9-2017.

Niederheiser, R., Rutzinger, M., Lamprecht, A., Steinbauer, K., Winkler, M., and Pauli, H., 2016. Mapping Alpine Vegetation Location Properties by Dense Matching. Int. Arch. Photogramm. Remote Sens. Spatial Inf. Sci., XLI-B5: 881-886.
Piermattei, L., Carturan, L., Guarnieri, A., 2015. Use of terrestrial photogrammetry based on structure from motion for mass balance estimation of a small glacier in the Italian Alps. Earth Surface Processing and Landforms, 40: 1791-1802.

Piermattei, L., Carturan, L., de Blasi, F., Tarolli, P., Dalla Fontana, G., Vettore, A., Pfeifer, N., 2016. Suitability of ground-based SfM-MVS for monitoring glacial and periglacial processes. Earth Surface Dynamics, 4: 325-443.

Rutzinger, M., Höfle, B., Lindenbergh, R., Oude Elberink, S., Pirotti, F., Sailer, R., Scaioni, M., Stötter, J., Wujanz, D., 2016. Close-Range Sensing Techniques in Alpine Terrain. ISPRS Ann. Photogramm. Remote Sens. Spatial Inf. Sci., 3(6): 15-22, DOI: 10.5194/isprs-annalsIII-6-15-2016.

Rutzinger and others 8, 2018. Training in Innovative Technologies for Close-Range Sensing in Alpine Terrain. ISPRS Ann. Photogramm. Remote Sens. Spatial Inf. Sci., 4(2).

Scaioni, M., Corti, M., Diolaiuti, G., Fugazza, D., Cernuschi, M., 2017a. Local and General Monitoring of Forni Glacier (Italian Alps) Using Multi-Platform Structure-From-Motion Photogrammetry. Int. Arch. Photogramm. Remote Sens. Spatial Inf. Sci., Vol. XLII-2, Part W7, pp. 1547-1554, doi: 10.5194/isprs-archives-XLII-2-W7-15472017.

Scaioni, M., Crippa, J., Longoni, L., Papini, M., Zanzi, L., 2017b. Image-Based Reconstruction and Analysis of Dynamic Scenes in a Landslide Simulation Facility. ISPRS Ann. Photogramm. Remote Sens. Spatial Inf. Sci., IV(5/W1): 63-70, DOI: 10.5194/isprs-annals-IV-5W1-63-2017.

Scaioni, M., Barazzetti, L., Corti, M., Crippa, J., Azzoni, R.S., Fugazza, D., Cernuschi, M., Diolaiuti, G., 2018b. Integration of Terrestrial and UAV Photogrammetry for the Assessment of Collapse Risk in Alpine Glaciers. Int. Arch. Photogramm. Remote Sens. Spatial Inf. Sci., 42(3/W4): 445-452, DOI: 10.5194/isprs-archives-XLII-3-W4-4452018.

Scaioni, M., Crippa, J., Yordanov, V., Longoni, L., Ivanov, V.I., Papini, M., 2018c. Some Tools to Support Teaching Photogrammetry for Slope Stability Assessment and Monitoring. Int. Arch. Photogramm. Remote Sens. Spatial Inf. Sci., 42(3/W4): 453-460, DOI: 10.5194/isprsarchives-XLII-3-W4-453-2018.

Wenzel, K., Rothermel, M., Fritsch, D., Haala, N., 2013. Image acquisition and model selection for multi-view stereo. Int. Arch. Photogramm. Remote Sens. Spatial Inf. Sci., 40(5W): 251-258.

\section{References from Websites:}

INTERMAP, 2018. NextMap $5^{\mathrm{TM}}$. Available online at: www.intermap.com/data/nextmap (last access on $5^{\text {th }}$ April 2018). 